\title{
Contradições gerenciais na disseminação da "cultura corporativa": o caso de uma estatal brasileira*
}

\author{
Alfredo Rodrigues Leite-da-Silva** \\ Gelson Silva Junquilho*** \\ Alexandre de Pádua Carrieri**** \\ Marlene Catarina de Oliveira Lopes Melo*****
}

S UMÁRIO: 1. Introdução; 2. As origens da “cultura corporativa”; 3. As abordagens de estudos sobre cultura em organizações e seus focos sobre os gestores; 4 . Críticas à abordagem integrativa de cultura: gestores em conflito na disseminação do consenso; 5. Agentes ambíguos ou gestores do prescrito? Dilemas nos níveis gerenciais da "ZIX"; 6. Conclusão.

S UMMARY: 1. Introduction; 2. The origins of 'corporate culture'; 3. Approaches to organizational culture studies and their focus on managers; 4 . Criticism in relation to the integrative approach: managers in conflict about the dissemination of consensus; 5 . Ambiguous agents or prescription managers? Dilemmas of the managerial levels at 'ZIX'; 6. Conclusion.

\footnotetext{
* Artigo recebido em maio e aceito em out. 2005.

** Aluno do doutorado em administração no Centro de Pós-Graduação e Pesquisas em Administração (Cepead), Face/UFMG. Mestre em administração pela Ufes. Endereço: Cepead/Face/UFMG - Rua Curitiba, 832, sala 1.202 - Centro - CEP 30170-120, Belo Horizonte, MG, Brasil. E-mail: arls@cepead.face.ufmg.br.

*** Professor do Programa de Pós-Graduação em Administração (PPGADM), Departamento de Administração/Ufes. Doutor em administração pela UFMG. Endereço: Departamento de Administração/CCJE/ Ufes - Avenida Fernando Ferrari, s/nํㅡ - Goiabeiras — CEP 29060-900, Vitória, ES, Brasil. E-mail: gelson@npd.ufes.br.

**** Professor do Centro de Pós-Graduação e Pesquisas em Administração (Cepead), Face/UFMG. Doutor em administração pela UFMG. Endereço: Cepead/Face/UFMG — Rua Curitiba, 832, sala 1.202 —Centro - CEP 30170-120, Belo Horizonte, MG, Brasil. E-mail: alexandre@ cepead.face.ufmg.br. ***** Diretora acadêmica e professora da Faculdade Novos Horizontes. Doutora em ciências das organizações pela Université de Paris IX, França. Endereço: Faculdade Novos Horizontes, Diretoria Acadêmica — Rua Alvarenga Peixoto, 1.270 — Santo Agostinho - CEP 30180-121, Belo Horizonte, MG, Brasil. E-mail: lenemelo@unihorizontes.br.
} 
PALAVRAS-CHAVE: cultura corporativa; empresa estatal; estudos organizacionais.

KE Y WORDS: corporate culture; state-owned companies; organizational studies.

Os que defendem as propostas da "cultura corporativa" vêem o gestor como um agente consensual, capaz de integrar os demais em uma cultura "única”. Os que se opõem a essas propostas focam a alienação e a exploração organizacional, instrumentalizada pelo gestor. Neste artigo, propõe-se extrapolar essa visão do gestor como apenas um agente consensual. Para isso, buscou-se evidenciar esses limites, ao confrontar as origens e as críticas dos estudos sobre "cultura corporativa" e destacar aspectos que podem levar o gestor a disseminar a diferença e a ambigüidade. Para embasar a argumentação foi apresentado um estudo de caso em uma regional da Empresa Brasileira de Correios e Telégrafos (ECT). Os dados foram coletados por meio de documentos e entrevistas semi-estruturadas, com 26 atores em diversos níveis gerenciais. O tratamento dos dados baseou-se na análise de conteúdo, buscando-se padrões ou recorrências de palavras, frases, idéias e tópicos de interesse. Concluiu-se que o gestor não pode ser considerado apenas elemento consensual, pois ele dissemina a integração e, também, a diferenciação e a fragmentação, permeado por objetivos e questões pessoais, sociais e organizacionais, não se limitando aos interesses da empresa.

Management contradictions on 'corporate culture' dissemination: the case of a Brazilian state-owned company

The advocates of 'corporate culture' proposals see the manager as an agent of consensus, capable of integrating others in a 'single' culture. Those who oppose such proposals focus on the organizational alienation and exploitation enforced by managers. This article proposes to extrapolate this perspective of the manager simply as an agent of consensus. It points out its limitations, contrasting the origins and criticisms of 'corporate culture' studies and underlining aspects that can lead the manager to disseminate differences and ambiguity. The argument is based on a study of a regional branch of the Brazilian Postal Service (Empresa Brasileira de Correios e Telégrafos - ECT). The data was collected in documents and semi-structured interviews with 26 subjects at different managerial levels. Data treatment was based on content analysis, in search of patterns or recurrences of words, sentences, ideas or topics of interest. The study concluded that the manager cannot be considered only an element of consensus, since he or she disseminates integration as well as differentiation and fragmentation, permeated by personal, social and organizational goals and issues, and not limited by the company's interests. 


\section{Introdução}

Desde fins da década de 1970, pesquisadores passaram a associar o sucesso da organização à gestão de elementos culturais em seu interior. Nessa abordagem, autores como Deal e Kennedy (1982) e Schein (1985) atribuem aos gestores a responsabilidade da construção de uma "cultura forte", na qual um sistema de regras formais e informais definiria claramente as ações e os comportamentos na organização. Durante a década de 1980, essa abordagem da "cultura corporativa" se firmou como a corrente predominante (Aktouf, 1994), colocando os gestores como responsáveis por administrar os sentidos, construir compartilhamentos consensuais, regular os conflitos, homogeneizar e integrar a organização (Pfeffer, 1981; Smircich e Morgan, 1982; Melo, 1991; Alvesson, 2002).

Aos gestores caberia, então, desenvolver ações para implantar a "cultura corporativa”, tendo como cerne as práticas de "gestão de pessoas”. Um conjunto de práticas capazes de viabilizar a transmissão das soluções dos problemas e controlar a cultura na organização. Tal abordagem se distancia do entendimento de autores como Davel e Vergara (2001), para os quais a "gestão de pessoas" deve estar de acordo com as contradições e paradoxos das relações de trabalho e com o papel de reconstrutor social do agente $^{1}$ organizacional. Aparentemente, a intenção é substituir, nesse papel, a ação do conjunto dos agentes pelos gestores. Assim, eliminam-se as contradições e paradoxos das relações de trabalho, por meio de uma suposta integração organizacional consensual, construída pelos próprios gestores, vistos, também, como um grupo homogêneo, sem dissensos e contradições.

A partir de sua disseminação, essas propostas receberam críticas diversas, a respeito da alienação do funcionário, da inobservância das bases antropológicas do conceito de cultura (Aktouf, 1994), da falta de atenção ao componente político (Rodrigues, 1991), entre outras. No entanto, um aspecto foi pouco explorado nessas críticas: o próprio gestor, ao se inserir naqueles paradoxos, pode ser fonte de diferenciação e fragmentação (Martin, 1992, 2002), dificultando, de forma consciente ou inconsciente, aquela suposta integração. Ele está "espremido" entre seus próprios valores e interesses, os de seus superiores e os de seus subordinados. Daí surgem freqüentes divergências e possíveis conflitos a serem mediados por um gestor que também está envolvido nessa dinâmica.

Portanto, é necessário investigar o gestor no papel de integrador, sem ignorar sua face de diferenciador e de fragmentador organizacional. Nesse sentido, em uma

\footnotetext{
${ }^{1}$ O termo agente é utilizado dentro da proposta de Chanlat (1996:29) de que são os “(...) indivíduos através dos seus atos que constroem a própria realidade social”, existindo em qualquer sistema social certa autonomia relativa do ser humano.
} 
perspectiva da gestão como "prática social” (Reed, 1989), propõe-se a discussão do papel do gestor ao atuar na integração organizacional. O que leva à questão a ser problematizada neste artigo: como se configura a atuação dos gestores em relação ao seu papel como componente de integração na proposta da "cultura corporativa"? Para tratar dessa questão, o artigo apresenta a origem dos estudos sobre "cultura corporativa”, as abordagens de estudos sobre cultura em organizações e seus focos sobre os gestores. Em seguida, desenvolve uma crítica às propostas integrativas de cultura e analisa dilemas e ambigüidades que podem evidenciar as contradições na atuação cotidiana dos gestores. A discussão é então embasada empiricamente pela análise de um estudo de caso, em uma regional da Empresa Brasileira de Correios e Telégrafos (ECT), a "ZIX”.2

\section{As origens da "cultura corporativa"}

As influências relacionadas com cultura nos estudos em organizações têm sua origem, aparentemente, na década de 1930, com Mayo (1960) na experiência de Hawthorne. Nessa experiência foram tratadas questões como os fatores sociais, o "sistema social irracional" e os "sistemas ideológicos simbólicos". Mas o termo cultura só foi utilizado, referindo-se ao contexto organizacional, no início da década de 1950, sendo Jaques (1951) um dos primeiros a defini-lo na expressão "cultura da empresa": um conjunto de idéias e ações mais ou menos compartilhadas a serem aprendidas e assumidas pelos novos membros da empresa, para que sejam aceitos.

Em fins da década de 1950, as atenções se voltaram para o movimento da "gestão comparativa”. De acordo com Smircich (1983), os estudos partiam de certo etnocentrismo norte-americano em uma visão de cultura como variável independente da ação organizacional. Em nível macro, examinavam as relações entre as culturas nacionais e a estrutura organizacional e, em nível micro, as semelhanças e diferenças entre as atitudes de gestores de diferentes culturas.

A partir de fins da década de 1970, com o crescimento da participação japonesa nos mercados ocidentais, os estudos focaram a cultura como variável dependente da ação organizacional. Nessa proposta, Ouchi (1986) se destacou ao investigar como alcançar o desempenho das organizações japonesas. O sucesso estaria em assumir as características das organizações norte-americanas bem-sucedidas, semelhantes às japonesas. Isso se tornaria possível pela repetição de histórias e even-

2 O nome é fictício, como solicitado pela organização. 
tos, constituindo símbolos, mitos, cerimônias e valores organizacionais, mesmo que fossem, até certo ponto, opostos à cultura da sociedade na qual a organização está inserida.

Na mesma abordagem, Peters e Waterman (1986) propõem a disseminação do sucesso de algumas organizações norte-americanas por meio da atuação dos gestores. Eles deveriam definir e reforçar os “valores comuns” ou a "cultura”, construindo um consenso que viabilizaria os objetivos organizacionais. Para isso, segundo Deal e Kennedy (1982), deve-se instrumentalizar os elementos da "cultura corporativa”: valores, heróis, ritos e rituais, mitos e tabus, e rede cultural. Ao trabalhá-los, os gestores construiriam uma cultura de base, com valores globais que direcionariam os indivíduos, eliminando as subculturas e os prejuízos que provocam.

Essas idéias foram compartilhadas por Schein (1985), para quem a cultura se basearia, em particular, naqueles que eram percebidos como criadores das soluções bem-sucedidas, com destaque aos primeiros, comumente os fundadores. Sua construção viria de um conjunto de suposições básicas. Após serem consideradas pelo grupo como soluções adequadas aos problemas de adaptação e integração, essas suposições seriam disseminadas. Vários autores, como Pépin (1998), não inserem Schein (1985) na corrente da "cultura corporativa”, mas na da "cultura organizacional”, principalmente, por ele não defender uma cultura generalista, vencedora em qualquer contexto. Diferenciando-se dos outros autores ao destacar que uma cultura adequada e consensual seria distinta de uma organização para outra.

Entretanto, essa distinção não será considerada aqui, pois as semelhanças entre as duas correntes são muitas: uma visão na qual é possível analisar e determinar a cultura dentro da ótica e dos limites corporativos, abordagens que "tinham a ousadia” de colocar "líderes culturais eficientes” na condição de criadores de culturas fortes, integradas e consensuais, de acordo com seus próprios valores (Martin e Frost, 2001:223). Características que enquadram a abordagem no que Martin (1992, 2002) identifica como perspectiva da “integração”, disseminando-se pelo mundo (Aktouf, 1994), em parte, por atender ao que Cavedon (1999) descreve como utilitarismo da ciência administrativa, ou por atrair os gestores pela possibilidade de eliminar orientações culturais diferentes das suas (Pépin, 1998). Mas, mesmo com tantos atrativos essa visão do gestor como controlador da cultura não é a única, assim como existem outras abordagens sobre cultura em organizações. 


\section{As abordagens de estudos sobre cultura em organizações} e seus focos sobre os gestores

Além das abordagens integrativas de cultura existem outras voltadas para a interpretação. Em vez do controle, busca-se a compreensão do contexto cultural na organização. A preocupação está em investigar aspectos como a heterogeneidade da cultura, as questões relativas ao poder e as diferenças sociais e profissionais de identidade (Pépin, 1998). Nessa linha, autores como Aktouf (1994), Dupuis (1996), Carrieri (2001), Cavedon e Fachin (2000), de diferentes maneiras, propõem o reconhecimento multidisciplinar da realidade local, das complexas características humanas e dos contextos sociais e culturais mais amplos, extrapolando os limites organizacionais.

Fica clara a diversidade dos estudos sobre cultura em organizações, distintos por diversos aspectos. Na busca por classificá-los Meyerson e Martin (1987), Frost e outros (1991) e Martin (1992, 2002) facilitam a compreensão das abordagens, sintetizando as diferenças em três dimensões:

t relação entre as manifestações culturais - foco na consistência organizacional, consistência grupal ou inconsistência;

t grau de consenso (homogeneidade) organizacional - foco no consenso organizacional, consenso grupal ou dissenso;

t orientação em relação à ambigüidade ${ }^{3}$ - foco na transparência organizacional, transparência grupal ou ambigüidade.

Segundo os autores, de acordo com os posicionamentos dentro dessas dimensões, os estudos sobre cultura em organizações se enquadram em quatro perspectivas:

t perspectiva da integração - foca a consistência das manifestações culturais (valores, interpretações...) e trata a organização como voltada para o consenso (homogeneidade) e a transparência. A ambigüidade é apenas um problema a ser resolvido para se alcançar a integração de todos;

\footnotetext{
${ }^{3}$ Segundo Martin (2002), é difícil conceituar claramente ambigüidade, mas ela envolve: a ignorância ou a confusão; as complexidades omitidas pelas oposições evidentes na reflexão dicotômica; e as tensões irreconhecíveis entre opositores, às vezes descritas como contradições, ironia ou paradoxos.
} 
t perspectiva da diferenciação — foca a consistência das manifestações culturais dentro de determinados grupos, nos quais existiria o consenso (homogeneidade) e a transparência. As subculturas se originam nas variáveis ambientais, ao atuarem por meio de mecanismos demográficos, sociais, de gênero, profissionais, entre outros. Entre grupos e subculturas existem diferenças e contradições que remetem às ambigüidades;

t perspectiva da fragmentação — foca a inconsistência entre as manifestações culturais, o dissenso e a ambigüidade na organização, pois está inserida num mundo de diversidade cultural, permeado por relações de interesses e consensos transitórios;

t “três perspectivas” — compreende estudos que utilizam as três perspectivas anteriores de maneira conjunta e complementar, cada uma das três possibilitando a explicação da composição de diferentes aspectos do contexto cultural de uma organização.

Em virtude de suas diferenças, os estudos enquadrados em cada uma dessas perspectivas colocam os gestores com atuações distintas, no tocante às mudanças culturais nas organizações.

t Na “integração” os gestores, por meio de práticas diversas, são os responsáveis pela ampla homogeneização organizacional, de forma integrada e consensual, a partir da criação de uma determinada cultura na organização (Meyerson e Martin, 1987).

t Na "diferenciação” os gestores se inserem em grupos e subculturas, podendo contribuir para a integração em seu interior e mediar as diferenças entre grupos distintos. Por exemplo, um membro organizacional pode, ao mesmo tempo, ser mulher, gerente e engenheiro, cada uma dessas características o inserem em subculturas distintas (Meyerson e Martin, 1987). As mudanças culturais envolvem construções externas e anteriores à organização e não se limitam às ações gerenciais.

t Na “fragmentação” os gestores são observados em um cenário confuso, no qual todos influenciam e são influenciados pelas subculturas, que os envolvem com significados irreconhecíveis. O foco não está mais na capacidade de instrumentalizar a cultura, mas nas ações para lidar com relações de poder e interesses pontuais e de curta duração. Essas relações envolvem grupos e indivíduos, inclusive os próprios gestores, em movimentações distintas, opostas ou favoráveis aos seus objetivos e aos da organização (Meyerson e Martin, 1987).

t Nas "três perspectivas" a atuação dos gestores pode incorporar tanto as ações voltadas para o consenso organizacional e grupal, quanto implicações de sua in- 
serção em subculturas distintas ou de suas relações cotidianas. São relações mais ou menos transitórias, de poder e de interesses, individuais e grupais, permeadas por ambigüidades que caracterizam o contexto organizacional (Martin, 1992).

Essa última possibilita um potencial de abstração que incorpora níveis de análise importantes para a discussão aqui proposta. Portanto, a abordagem das "três perspectivas" foi adotada como alternativa teórico-metodológica neste artigo. Ao se discutir as ações e os agentes voltados para a integração é necessário optar por uma abordagem que inclua possíveis ambigüidades, oriundas de diferenciações e fragmentações.

Essas ambigüidades surgem nos diferentes papéis assumidos pelos gestores, ao se envolverem em mudanças culturais, muitas vezes simultâneas, com características diversas. Tal entendimento vai ao encontro das proposições de Alvesson (2002), que identifica três tipos de mudança cultural, possivelmente simultâneas:

t "o grande projeto" - um projeto no qual amplos recursos gerenciais são investidos em uma determinada mudança cultural, planejada pelo topo da hierarquia organizacional;

t "o movimento orgânico" - ocorrem mudanças culturais que, além de serem apoiadas pela alta direção e o escopo organizacional, são impulsionadas, principalmente, pela movimentação social sem, necessariamente, a atuação de lideranças específicas;

t e a "reconstrução cotidiana" - mudanças culturais para as quais agentes ou grupos podem atuar de forma central, crescente e informal, sem planejamento ou objetivos.

Esses dois últimos tipos de mudança cultural têm implicações com o potencial de afastar os próprios gestores dos objetivos organizacionais. No "movimento orgânico" as pressões externas, como as preocupações com o meio ambiente, podem impulsionar os gestores para um posicionamento em desacordo com aqueles objetivos organizacionais declarados. Na "reconstrução cotidiana" o próprio gestor pode interagir com outro agente ou agentes, como os sindicalistas, que o levem a refletir sobre idéias e valores diferentes daqueles objetivados pela organização. Os dois tipos de mudanças culturais podem ocorrer simultaneamente, ambos implicam 
ambigüidades na atuação dos gestores. Isso evidencia as limitações das propostas de integração cultural, ao colocarem os gestores como principais responsáveis pelo desenvolvimento de ações em prol do "grande projeto" de integrar a organização.

4. Críticas à abordagem integrativa de cultura: gestores em conflito na disseminação do consenso

As críticas à visão integrativa de cultura em organizações se concentram no fato de ela subestimar as relações de poder, conflitos e processos de regulação inerentes às estruturas sociais. A compreensão da complexa subjetividade humana é simplificada em dimensões instrumentalizáveis por meio de um reducionismo. Oculta-se, sob o discurso da construção de uma cultura comum que atenderia a todos, um movimento para constituir instrumentos de dominação (Pagès et al., 1987) e de limitação da irracionalidade (Pépin, 1998). Ao se propor, neste artigo, problematizar esse posicionamento, há o reconhecimento de que o gestor, mesmo tendo a atribuição de assumir o discurso "mais adequado" aos "interesses” da organização, está submetido a diversas influências, muitas das quais internalizadas ao longo de sua história de vida. Os grupos sociais com os quais conviveram e os contextos culturais nos quais seus quadros de valores e referências foram construídos não são simplesmente ignorados ou apagados por todos os que passam a fazer parte do "seleto" grupo gerencial.

A capacidade de mudar, alterando construções internalizadas, não é algo totalmente instrumentalizável a favor dos interesses organizacionais, nem mesmo pelo indivíduo no tocante a ele próprio. Aqui se defende a idéia de "construção social da realidade”, no entendimento de Berger e Luckmann (1985), como uma inter-relação entre construções que não mudam completamente, nem são totalmente estáticas, pois envolvem negociações interpessoais relacionadas com histórias e experiências comuns. Assim se reforçam ou alteram aspectos da ordem social, sempre produzida, mas muitas vezes percebida, como "algo dado", "natural”, “o certo”, “a verdade”, o que apenas expõe contornos dessa ordem social.

Portanto, como qualquer agente social, fazendo parte ao longo de sua vida de diversos grupos sociais, o gestor convive com uma cultura geral, mas também com diversas subculturas, sendo produtor e produto delas (Melo, 1991). Isso se refletirá em suas interações no interior das organizações. Ao apresentar e discutir essas interações, Aktouf (1994) propôs tratá-las com base em aspectos centrais, constitutivos e fundamentais de uma cultura. Esses aspectos são chamados, aqui, de elos da complexidade das relações organizacionais, ou seja, relacionamentos em comum nos grupos sociais, constituídos por um conjunto complexo e multidimensional na interdependên- 
cia da "história”, das "experiências subjetivas das pessoas”, das “condições de vida”, da "estrutura social”, em relações dialéticas “concreto-econômicas”, "sociais” e "simbólicas”. Tais elos compõem culturas de "oposição ou de clivagem” no interior de uma mesma comunidade, envolvem a ligação do "imaterial” com o "material” por “(...) um complexo coletivo de representações mentais (...)” (Aktouf, 1994:49-53).

As preocupações com a historicidade, com os simbolismos, com o aspecto temporal, com as relações socioeconômicas, de poder e de conflito, evidenciam-se nas afirmações daquele mesmo autor. A partir dessas afirmações, pode-se vislumbrar a possibilidade dos gestores viverem dilemas, no seu cotidiano, entre os interesses organizacionais que, supostamente, devem defender, e suas próprias convicções que, não necessariamente, acompanham aqueles interesses.

Esse entendimento está de acordo com a crítica de Rodrigues (1991:58), para quem a cultura, na ótica funcionalista, visa “(...) transformar questões de natureza política, como valores e interesses, em questões puramente técnicas”. Segundo a autora, a “cultura corporativa” é colocada como resultado do controle de elementos como os valores e os mitos, reduzindo a "lógica da cultura” à da "racionalidade formal”. Logo, simplificar o papel do gerente, como um suposto "coordenador técnico”, no controle daqueles elementos, implicaria ignorar possíveis dilemas e ambigüidades provenientes da "natureza política” daquelas questões e dos agentes sociais envolvidos.

Para Alvesson e Willmott (1996), subestimar a dimensão social da gestão diminui a compreensão sobre as dificuldades e os desafios de gerenciar pessoas, de se lidar com distinções de valores, objetivos e recursos que permeiam as relações entre os próprios gestores e deles com os demais agentes. Relações que, segundo os autores, podem levar o gestor a sofrer com as reações dos subordinados, fazê-lo buscar justificativas racionais para suas próprias ações, ou deixá-lo desnorteado. Nesse processo, os gestores se caracterizam pela ambigüidade em relação à estrutura de dominação da organização, sendo submetidos à mesma ordem que lhes delega o controle sobre seus subordinados, podendo "adotar, praticamente, tantas tomadas de posição diferentes quantas são as diferentes definições de sua posição” (Boltanski, 1984:19).

A ambigüidade está presente em todos os níveis organizacionais, sendo mais intensa nos níveis gerenciais intermediários (Motta, 2002). Seus membros estão distantes e, ao mesmo tempo, pressionados pela cúpula e pela base organizacional. Assim podem ser responsabilizados pelas decisões e desempenho de ambos. Os níveis mais altos da hierarquia tendem a externar posicionamentos consensuais e/ou de passividade em relação a uma determinada situação ou decisão, mas podem, de forma menos evidente, sabotar os objetivos pretendidos, demonstrando que não os com- 
partilham (Smircich e Morgan, 1982). Uma justificativa, para esse tipo de comportamento, pode estar na preocupação do gestor em sobreviver na carreira gerencial e no seu conseqüente impulso para a lógica do desenvolvimento contínuo (Melo, 2000).]

Observa-se, em concordância com Alvesson e Sveningsson (2003), que os gestores atuam em um contexto ambíguo, sendo essa uma característica dos cotidianos organizacionais em geral, nos quais eles mediam situações complexas e contraditórias. Os gestores também estão inseridos nessas situações, o que influencia suas próprias internalizações. No entanto, apesar de toda a discussão sobre o gerenciamento cultural na organização - e talvez por causa dela - , a questão dos valores pessoais, das subculturas, das relações de poder e dos interesses individuais, grupais, profissionais e organizacionais não é tratada em profundidade como fonte de ambigüidades para o gestor.

Para lidar com essa realidade, as discussões sobre cultura em organizações devem incorporar a definição de Reed (1989) de gestão como prática social, ou seja, envolver de maneira imbricada as estruturas organizacionais formais, as regulações de conflitos decorrentes das relações de poder e de interesses divergentes e convergentes. Também envolve os conflitos políticos entre grupos, inseridos em estruturas de relações de poder e de controle, produzidas e reproduzidas nas organizações. Surge, então, o gestor como agente social, responsável pela defesa dos interesses organizacionais e, ao mesmo tempo, vivenciador de conflitos e contradições, dilemas ligados aos objetivos organizacionais, aos interesses dos grupos dos quais faz parte, e às suas convicções pessoais.

Toda a discussão apresentada até aqui expõe a complexidade da problematização inicialmente proposta. As conversações com e entre os autores citados indicam que os gestores, em relação ao seu papel como componente de integração na construção de uma "cultura corporativa", não são os únicos a fazerem parte da construção social da realidade. Vê-se que eles também não se limitam aos interesses organizacionais. A implementação de uma determinada "cultura corporativa" é apenas mais um processo dentro de uma construção mais ampla. A "cultura corporativa" não está livre de contradições e ambigüidades, oriundas das inter-relações inerentes aos aspectos humanos envolvidos, como as relações dialéticas "concreto-econômicas”, "sociais" e "simbólicas".

O papel de integrador, legitimado pela autoridade concedida ao gestor pela alta direção, não é totalmente eliminado. Muitas vezes, no tocante a determinadas questões e posicionamentos, o gestor pode atuar em consonância com os interesses organizacionais. Dessa forma propicia uma direção consensual e contribui para a in- 
tegração de aspectos de uma “cultura corporativa” intencionada pela alta direção organizacional. Entretanto, deve ficar claro que ele não se limita a esse papel, sendo necessário reconhecer o gestor como origem de integrações, diferenciações e fragmentações nas culturas em organizações. Esse seria o caminho que possibilitaria uma maior compreensão das relações entre a atuação gerencial e os contextos culturais.

Para embasar empiricamente essas considerações, a seguir apresenta-se um estudo de caso sobre as percepções de gestores relacionadas com a disseminação de uma “cultura corporativa”. Investigam-se possíveis integrações, diferenciações e fragmentações relacionadas com a atuação gerencial.

\section{Agentes ambíguos ou gestores do prescrito? Dilemas nos níveis gerenciais da "ZIX”}

\section{Aspectos metodológicos da investigação}

Para a coleta e a análise dos dados adotou-se a abordagem qualitativa. O foco está em níveis mais profundos da realidade, não se pretende medir, mas sim explorar e revelar fenômenos relacionados com valores, atitudes, crenças, significados e motivações (Minayo, 2001). Por dar suporte à natureza qualitativa do estudo, de forma detalhada e aprofundada, a delimitação proposta levou ao desenvolvimento de um estudo de caso (Yin, 2001). Esse estudo se deu com múltiplas fontes de evidências, para ampliar a abrangência da pesquisa (Triviños, 1987).

A pesquisa se iniciou pelo levantamento bibliográfico, em seguida, foram feitos os primeiros contatos com a empresa, coletados dados e solicitados documentos, o que permitiu as definições dos critérios para as delimitações:

t das unidades a serem investigadas: maior volume de operação, receita e número de funcionários;

t do período a ser investigado: de 1988 a 2001 — gestão de uma diretoria voltada para a criação de uma "cultura corporativa”;

t dos sujeitos da pesquisa: maior tempo de exercício de função gerencial na "ZIX”, de 1988 a 2001, com um limite mínimo de três anos. 
O foco no grupo gerencial se deveu ao fato de ter sido atribuída a ele, indistintamente, a responsabilidade pela disseminação da "cultura corporativa". Portanto, os gestores foram tratados como um grupo único, sem diferenciação hierárquica, optando-se por não classificar as percepções de acordo com cada categoria, bem como se optou por "perder" as questões referentes aos demais funcionários. Ambas as opções se justificam pelo fato de o problema de pesquisa não exigir o mapeamento de toda a diversidade organizacional, mas sim a vivenciada pelos agentes sociais inseridos no papel de gestor.

Uma opção semelhante foi feita por Cavedon e Fachin (2000), que em uma investigação delimitaram a análise em três grupos: professores, alunos e funcionários. Ao tratá-los de forma homogênea optaram por "perder" as diferenças intragrupos, por exemplo, entre secretárias e assistentes administrativos, todos inseridos no grupo de funcionários. Essa foi uma perda que não prejudicou os resultados da pesquisa e possibilitou focar a questão a ser problematizada na investigação. Portanto, o foco nos gestores atende aos objetivos do estudo, ainda que possa ser uma limitação, ao implicar "perda” de parte da compreensão do contexto cultural.

Com base nesse foco, e nos critérios de seleção, identificou-se um grupo de 92 agentes sociais. Ao se concordar com Poirier e colaboradores (1983), segundo o qual 20 a 30 sujeitos já permitem a saturação de informações em investigações semelhantes, o grupo foi reduzido para 26 agentes sociais. Todos os níveis gerenciais da "ZIX" foram contemplados, com maior concentração de representantes da área de "recursos humanos" e de ocupantes de cargos em níveis gerenciais mais altos, diretamente responsáveis pela definição e disseminação da "cultura corporativa”. O grupo de sujeitos foi composto da seguinte maneira:

t o diretor regional; ${ }^{4}$

t todos os membros da assessoria da diretoria regional - três assessores e dois coordenadores;

t todos os ocupantes de cargos de gerente - oito gerentes;

t todos os chefes de seção e metade dos supervisores da área de "recursos humanos" - três chefes de seção e dois supervisores;

\footnotetext{
${ }^{4}$ Diretor que atuou na “ZIX” no período investigado, de 1988 a 2001.
} 
t sete representantes dos demais níveis de chefia, escolhidos com base na proporção do total de gestores em cada nível — dois chefes de seção, um chefe de Centro de Distribuição Domiciliar, dois chefes de agência e dois supervisores.

A partir da definição do grupo de sujeitos da pesquisa iniciaram-se as entrevistas semi-estruturadas em conjunto com a análise de documentos. Os dados foram analisados por meio da análise de conteúdo, seguindo a proposta de Bardin (1977). Essa técnica permite a organização sistemática dos dados em unidades manipuláveis, no caso "temas": a parte de um texto que expressa determinados significados, em recortes baseados no referencial teórico, permitindo o estudo de “(...) motivações de opiniões, de atitudes, de valores, de crenças, de tendências” (Bardin, 1977:106).

A partir das entrevistas, por meio da observação de padrões ou recorrências em palavras, frases, idéias e tópicos de interesse (Bogdan e Biklen, 1994), foram evidenciados 15 temas de análise capazes de agrupar os demais temas. Isso se deu em virtude da similaridade semântica, no tocante às questões mais gerais a que se referem, quais sejam:

t percepções dos construtores sobre a obra;

t o diretor e a reprodução de seus valores;

t construtores da cultura;

t monitoramento, avaliação e controle;

t integração;

t valorização;

t formação dos agentes;

t valores na organização;

t intenções organizacionais;

t comunicação;

t contradições e paradoxos das relações de trabalho;

t descontentamentos dos agentes;

t relação com o sindicato;

t significados das políticas de "RH";

t papel das lideranças. 
Cada uma delas configurou uma categoria de análise que permitiu classificar os temas expressos pelos sujeitos e analisar, de maneira mais aprofundada, as questões por eles destacadas. Tal procedimento propiciou a definição dos extratos das entrevistas a serem mencionados na discussão dos resultados da pesquisa, pelo critério da maior capacidade de representar as significações e os níveis de compartilhamentos organizacionais observados.

\section{Um pouco da história da "ZIX”}

Os anos 1930 marcaram a criação do Departamento de Correios e Telégrafos no Brasil, e o surgimento da "ZIX"5 como uma das diretorias regionais. Em 1969, durante o regime militar, com a criação da Empresa Brasileira de Correios e Telégrafos (ECT), foram realizados novos investimentos e a profissionalização. Nessa fase, vários cargos foram ocupados por militares, até o final da década de 1980, origem de algumas características da organização presentes até a atualidade.

Especificamente na "ZIX", outras fortes influências surgiram a partir de 1988, com a posse de um diretor que passou a gerenciar com base no slogan “equipe, trabalho e lealdade”. Em 1993, além de outras mudanças, a regional passou a priorizar o projeto "gerenciamento de desempenho", para dar suporte ao gerenciamento por diretrizes, implementando mudanças no sistema de avaliação das lideranças que, em 1994, passaram a fazer cursos, para que se propagasse a "filosofia” da qualidade total. Ao mesmo tempo, ocorre a criação do Comitê de Implantação da Qualidade Total (CIQT). A partir das ações desse comitê, em 1997, a "ZIX" aderiu ao Programa Nacional de Qualidade dos Correios (PNQC), e ao Prêmio Qualidade do Governo Federal. Logo se destaca que essa ênfase na qualidade não ocorre apenas em nível local, mas está inserida no contexto nacional, em ações do governo federal voltadas para ampliar a competitividade das organizações estatais brasileiras.

Em 2001, o então diretor se afastou, fechando um ciclo iniciado com aquele slogan "equipe, trabalho e lealdade", até os três pilares que, em 2001, baseavam seu plano de trabalho: "lucratividade, qualidade e harmonia". Esse período foi marcado pela intenção de preparar os funcionários em cargos gerenciais para assumirem um novo papel na "gestão de pessoas": envolver os funcionários e direcioná-los para construírem compartilhamentos mais adequados aos interesses de "todos".

Em 2002, ano da pesquisa, a ECT atuava em todos os municípios brasileiros, por meio de 90 mil empregados, contando com 12 mil agências, uma frota de mais

\footnotetext{
${ }^{5}$ As informações sobre a história da "ZIX" foram obtidas por meio de documentos internos e entrevistas com funcionários. Os dados bibliográficos referentes a essas fontes não foram revelados por solicitação da organização.
} 
de 9 mil veículos e 26 linhas aéreas. Já a "ZIX” possuía em torno de 1.500 funcionários, distribuídos em sete gerências, três regiões operacionais estaduais e 16 centros de distribuição domiciliários.

Análise das percepções dos gestores

Integrações, diferenciações e fragmentações nas ações gerenciais para a integração

A partir da análise dos depoimentos dos gestores foi possível evidenciar três tipos de questões relacionadas com o contexto cultural na "ZIX": as que vão além do contexto organizacional, oriundas das relações dos indivíduos na sociedade; as que estão em reprodução há muitos anos na organização; e as construídas a partir de recentes relações organizacionais, algumas a partir da interferência gerencial, outras não. Apesar de existir certo imbricamento entre os três tipos, para fins de análise é necessário destacá-los para entender suas relações em direções convergentes, divergentes ou distintas no cotidiano da organização.

Quando são convergentes, elas tendem a reforçar determinado compartilhamento consensual integrado por todos na organização. Quando são divergentes ou distintas surgem, respectivamente, oposições e novas questões que levam à diferenciação e/ ou fragmentação. De maneira recorrente, os depoimentos dos gestores indicaram a existência de construções em direção do consenso, da oposição e de distinções relacionadas com seu papel de integrador. A conotação, ao mencionarem essa diversidade de direções, em alguns casos podia ser negativa, em outros, positiva, mas era colocada, em síntese, como uma realidade com a qual conviviam, envolvendo uma variedade de questões e ações. Isso pode ser observado no quadro, ao sintetizar as percepções dos gestores em relação ao impacto de algumas ações para a integração, no sentido do consenso geral (integração); do consenso grupal (diferenciação); dos dilemas e das ambigüidades (fragmentação). 


\begin{tabular}{|c|c|c|c|}
\hline \multicolumn{4}{|c|}{$\begin{array}{c}\text { Integrações, diferenciações e fragmentações nas ações gerenciais para a } \\
\text { integração }\end{array}$} \\
\hline \multirow{2}{*}{$\begin{array}{l}\text { Ações para a } \\
\text { integração e níveis ger- } \\
\text { enciais dos } \\
\text { sujeitos das } \\
\text { percepções }\end{array}$} & \multicolumn{3}{|c|}{$\begin{array}{l}\text { Percepções dos gestores em relação ao impacto das } \\
\text { ações para a integração e sujeitos que as evidenciaram no sentido: }\end{array}$} \\
\hline & $\begin{array}{l}\text { do consenso } \\
\text { geral } \\
\text { (integração) }\end{array}$ & $\begin{array}{l}\text { do consenso } \\
\text { grupal } \\
\text { (diferenciação) }\end{array}$ & $\begin{array}{l}\text { dos dilemas e das } \\
\text { ambigüidades } \\
\text { (fragmentação) }\end{array}$ \\
\hline $\begin{array}{l}\text { Usar as políticas de } \\
\text { “RH” para integrar a } \\
\text { organização }\end{array}$ & $\begin{array}{l}\text { Contribui para a } \\
\text { integração, que } \\
\text { beneficia o gestor, } \\
\text { ao mesmo tempo } \\
\text { que depende dele }\end{array}$ & $\begin{array}{l}\text { Cria grupos de } \\
\text { beneficiados e } \\
\text { prejudicados, entre } \\
\text { outras afinidades }\end{array}$ & $\begin{array}{l}\text { Envolve aspectos } \\
\text { organizacionais e } \\
\text { pessoais, implica } \\
\text { pressões e dilemas } \\
\text { sobre o gestor e varia } \\
\text { pela sua iniciativa e } \\
\text { carga de trabalho }\end{array}$ \\
\hline $\begin{array}{l}\text { Sujeitos das } \\
\text { percepções } \\
\text { na alta gerência }\end{array}$ & $\begin{array}{l}\text { Diretor 1; Assessores } \\
1,2 \text { e } 3 \text {; } \\
\text { Coordenadores } \\
1 \text { e } 2 \text {; Gerentes } 1,2,3 \text {, } \\
4,5,6,7 \text { e } 8\end{array}$ & Gerentes 1, 2, 4 e 6 & $\begin{array}{l}\text { Assessores 1, } 2 \text { e 3; } \\
\text { Coordenadores } 1 \text { e 2; } \\
\text { Gerentes 1, 2, 4, } 6 \text { e } 7\end{array}$ \\
\hline $\begin{array}{l}\text { Sujeitos das } \\
\text { percepções nos } \\
\text { demais níveis } \\
\text { gerenciais }\end{array}$ & $\begin{array}{l}\text { Chefe de agência 1; } \\
\text { Chefe de CDD 1; } \\
\text { Chefes de seção } 1,3 \text { e } \\
\text { 4; Supervisores } 1,2,3 \\
\text { e } 4\end{array}$ & $\begin{array}{l}\text { Chefe de CDD 1; } \\
\text { Chefe de seção } 3\end{array}$ & $\begin{array}{l}\text { Chefe de agência 2; } \\
\text { Chefe de CDD 1; } \\
\text { Chefe de } \\
\text { seção 3; Supervisores } \\
2,3 \text { e } 4\end{array}$ \\
\hline $\begin{array}{l}\text { Disseminar valores } \\
\text { voltados à integração: } \\
\text { igualdade, honestidade, } \\
\text { transparência, } \\
\text { comprometimento... }\end{array}$ & $\begin{array}{l}\text { Propicia o consenso } \\
\text { sobre os significados } \\
\text { dos valores e o } \\
\text { reconhecimento da sua } \\
\text { importância para todos }\end{array}$ & $\begin{array}{l}\text { Coloca uns como } \\
\text { “mais” alinhados com } \\
\text { os valores do que } \\
\text { “outros”, criando } \\
\text { grupos e significados }\end{array}$ & $\begin{array}{l}\text { Cria sofrimento e } \\
\text { dilemas quando } \\
\text { mudanças geram } \\
\text { incertezas, altera o } \\
\text { grupo dos “mais” e dos } \\
\text { “outros” e remete à } \\
\text { redefinição de práticas, } \\
\text { significados e valores }\end{array}$ \\
\hline $\begin{array}{l}\text { Sujeitos das } \\
\text { percepções na } \\
\text { alta gerência }\end{array}$ & $\begin{array}{l}\text { Diretor 1; Assessores } \\
\text { 1, } 2 \text { e } 3 \text {; } \\
\text { Coordenadores } \\
1 \text { e } 2 \text {; Gerentes 2, 3, 4, } \\
5,7 \text { e } 8\end{array}$ & Gerente 6 & $\begin{array}{l}\text { Diretor } 1 \text {; Assessores } \\
1 \text { e 2; Coordenador } 1 \text {; } \\
\text { Gerentes } 2 \text { e } 7\end{array}$ \\
\hline
\end{tabular}




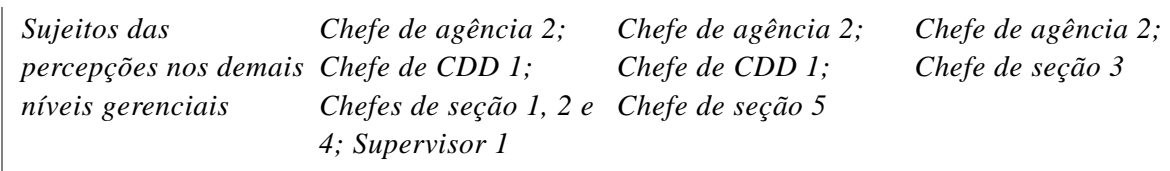

continua

Ações para a

integração e níveis ger-

enciais dos

sujeitos das

percepções

Avaliar com

neutralidade, beneficiando o

“bom”funcionário e

resgatando o "mau” gração)

Promove a integração, Cria e reforça grupos, Segue interesses: sendo necessário de acordo com a demitir quando o avaliação de quem é resgate for "bom" ou "mau" impossível

Percepções dos gestores em relação ao impacto das ações para a integração e sujeitos que as evidenciaram no sentido:

$\begin{array}{ccc}\begin{array}{c}\text { do consenso } \\ \text { geral }\end{array} & \begin{array}{c}\text { do consenso } \\ \text { grupal }\end{array} & \begin{array}{c}\text { dos dilemas e das } \\ \text { ambigüidades }\end{array} \\ \text { (integração) } & \text { (diferenciação) } & \text { (fragmentação) }\end{array}$

pessoais...; e contradições: "mau” funcionário beneficiado sobre o "bom"; impunidade no resgate...

Assessor 2; Gerentes 2, 4, 6 e 7

e 3; Coordenadores 1 e

2; Gerentes 1, 2, 4 e 5

Chefes de agência Chefe de CDD 1; 1 e 2; Chefe de CDD 1; Chefes de seção Chefe de seção 2 3, 4 e 5

percepções nos demais níveis gerenciais

Propiciar o aperfeiçoamento e o crescimento profissional do empregado

Dissemina e integra a idéia de que o aperfeiçoamento contínuo é necessário e vantajoso para todos

Sujeitos das Coordenador 1; percepções na alta gerência

\section{Gerentes 4, 6 e 8}

Gerentes 6, 7 e 4

Divide a organização entre os que "têm ou não” o privilégio e a vontade para crescer e se aperfeiçoar

Sujeitos das Chefe de agência 1; percepções nos demais níveis gerenciais
Chefe de CDD 1;

Supervisor 2
Chefe de CDD 1;

Chefe de seção 3
Chefe de agência 2;

Chefe de CDD 1;

Chefes de seção 3 e 5; Supervisores 2 e 4

Leva a interesses distintos, por vezes contraditórios: estabilidade, carreira, empregabilidade, salário, objetivos organizacionais...

Assessor 1;

Coordenador 1;

Gerentes 6 e 7

Chefe de agência 2;

Chefe de seção 3 
O quadro revela que os mesmos gestores apresentam dois ou três direcionamentos simultâneos. Algumas vezes, são complementares em relação a uma mesma ação, havendo coerência entre eles. Entretanto, em outras, não se observa essa complementaridade e se evidenciam até incompatibilidades. O que revela certa incoerência, na manifestação de alguns desses direcionamentos pelo mesmo gestor. Isso pode ser mais bem entendido tomando-se dois exemplos distintos. O primeiro parte do seguinte fragmento:

[O funcionário] não pode ser só ajustado, motivado e treinado, tem que estar comprometido (...) [Mas] O funcionário vai sofrer se ele tiver o comprometimento, se ele tiver um treinamento e não tiver um comprometimento ele não sofre (...) Então você tem que tomar cuidado na questão de uma transferência no que ele está passando (...) com um funcionário que está comprometido, você tem que fazer com que ele mude para cima, melhorando, nunca para baixo.

(Diretor 1)

Esse fragmento trata da segunda ação para a integração apresentada no quadro: disseminar valores voltados à integração... Como se observa no quadro, as percepções dos gestores em relação ao impacto dessa ação para a integração se evidenciaram em três sentidos:

t consenso geral (integração), expresso pelos sujeitos Diretor 1; Assessores 1, 2 e 3; Coordenadores 1 e 2; Gerentes 2, 3, 4, 5, 7 e 8; Chefe de agência 2; Chefe de CDD 1; Chefes de seção 1, 2 e 4 e Supervisor 1, pois todos manifestaram em seus depoimentos a idéia de que tal ação propicia o consenso sobre os significados dos valores e o reconhecimento da sua importância para todos (ver quadro);

t do consenso grupal (diferenciação), expresso pelos sujeitos Gerente 6; Chefe de agência 2; Chefe de CDD 1; Chefe de seção 5, pois todos manifestaram em seus depoimentos a idéia de que tal ação coloca uns como "mais" alinhados com os valores do que "outros", criando grupos e significados (ver quadro);

t dos dilemas e das ambigüidades (fragmentação), expresso pelos sujeitos Diretor 1; Assessores 1 e 2; Coordenador 1; Gerentes 2 e 7; Chefe de agência 2; Chefe de seção 3 , pois todos manifestaram em seus depoimentos a idéia de que tal ação cria sofrimento e dilemas quando mudanças geram incertezas, alteram o grupo dos "mais" e dos "outros" e remetem à redefinição de práticas, significados e valores (ver quadro). 
O primeiro fragmento evidencia dois desses sentidos no depoimento do Diretor 1: a integração e a fragmentação. Além dele, como mostra o quadro, os Assessores 1 e 2, o Coordenador 1, os Gerentes 2 e 7, o Chefe de agência 2 e o Chefe de seção 3 também apresentaram percepções sobre a ação em questão que a remete para a integração e a fragmentação. Isso é coerente pelo fato da intensidade da fragmentação estar ligada à da integração. A primeira surge com as mudanças — como uma redução de pessoal ou alteração no sistema de avaliação — , desde que, antes, exista a segunda, como uma visão consensual internalizada sobre o significado e a importância de determinados valores, tal qual o comprometimento. Portanto, há certa coerência quando o mesmo gestor indica, de maneira ambígua, dois sentidos referentes à mesma ação. Entretanto, nem sempre existe essa coerência entre o sentido da integração e o da fragmentação (bem como o da diferenciação), como pode ser observado no segundo exemplo, a partir do seguinte extrato de entrevista:

nós temos situações, tipo na área operacional que trabalha por produção que você consegue medir muito bem a questão da produtividade (...) então isso daí já é um ponto de avaliar a questão do bom ou mau funcionário, a questão do GCR [gerenciamento de competência e resultados].

(Gerente 4)

infelizmente teve muita gente que não merecia promoção e foi beneficiada. (...) eu sempre defendi, é essa questão do cara ruim ter que responder pelos erros dele, ele tem que ser responsável pelo mau desempenho, ele tem que ser treinado, negociado e ele tem que dar o dele, procurar se desenvolver, pra poder crescer (...).

(Gerente 4)

Os dois fragmentos estão relacionados com a terceira ação para a integração apresentada no quadro: avaliar o funcionário com instrumentos neutros, beneficiando o “bom” e resgatando o “mau”. Nesse caso há certa incoerência nos sentidos da integração e da fragmentação. Assim como o Gerente 4 expressou a integração e a fragmentação nesses fragmentos, o quadro mostra que também o Gerente 2, o Chefe de agência 2 e o Chefe de CDD 1 apresentaram percepções remetendo essa ação tanto para o sentido do consenso (integração), pois promove a integração, sendo necessário demitir quando o resgate for impossível (ver quadro), quanto para o da fragmentação, pois segue interesses: organizacionais, pessoais...; e contradições: “mau” funcionário beneficiado sobre o "bom"; impunidade no resgate... (ver quadro). A neutralidade contribuiria para a integração ao legitimar a definição de quem é “bom” ou "mau” e os possíveis demitidos. Mas tal entendimento não é coerente com o de que a avaliação 
segue interesses organizacionais e pessoais na definição do "bom" e do "mau" funcionário. Os dois entendimentos são contraditórios e excludentes. Logo, os diferentes sentidos dessa ação, a despeito de poderem ser expressos pelos mesmos gestores, são incoerentes, reforçando a ambigüidade de um contexto permeado por discursos e ações contraditórios.

Em síntese, as questões podem convergir para o consenso em um movimento de integração. Ou podem divergir, ou se diferenciar, em um movimento de fragmentação e diferenciação. Esses direcionamentos surgiram de maneira conjunta nos depoimentos, mas nem sempre existia coerência entre eles, o que pode indicar a ambigüidade gerencial. Isso se evidenciou na análise do conteúdo dos depoimentos, como se observa no quadro, que fornece um embasamento empírico para a crítica das propostas de autores para os quais os gestores são "integradores da cultura". O que se observou na pesquisa foram gestores não apenas "integradores”, mas, também, “diferenciadores” e "fragmentadores”. Eles são agentes sociais em complexas e ambíguas relações cotidianas, permeados por interesses e dilemas de origem pessoal e organizacional. Esse é o contexto no qual os gestores atuam, permeado por consensos e dissensos que envolvem suas ações, impossibilitados de isolá-las dos dilemas com os quais têm de conviver.

As ações dos gestores e seus dilemas

As ações concentradas nos níveis de chefia objetivavam a disseminação de determinadas idéias por toda a "ZIX". Ao longo do tempo, formaram-se comitês compostos pelos gestores de diversas áreas. O primeiro deles, o da qualidade, surgiu em 1994; o segundo, o da lucratividade, em 1996; e por fim, em 1999, surgiu o da harmonia, com o objetivo de dar suporte aos dois anteriores ao tratar das pessoas. A composição desses comitês reforçava a proposta de participação e entrosamento dos gestores, presente no discurso da alta direção.

Por exemplo, [o comitê] lucratividade tem gente da financeira, tem gente da área de vendas, tem gente da operação, porque eles querem se reunir para lutar pela lucratividade; qualidade tem gente da financeira, tem gente da área de "recursos humanos". (...) Então, os três comitês são o suporte da diretoria que, além dela ter a parte hierárquica, tem essa parte matricial, na qual os comitês é que fazem a gestão.

(Gerente 8)

As ações desses comitês visavam o envolvimento de todos os membros organizacionais em torno dos interesses da organização. Para contribuir com esse objetivo, 
buscou-se disseminar valores supostamente voltados à integração, tais como: igualdade, honestidade, transparência e comprometimento. Nesse processo os papéis do diretor, da área de "recursos humanos" e dos chamados líderes — os membros de todos os níveis gerenciais - foram destacados como preponderantes. Entretanto, a despeito do papel a eles atribuído, vários desses gestores afirmaram não acreditar em algumas propostas que deviam repassar, conforme pode ser observado no seguinte depoimento:

\begin{abstract}
Será que é tão importante você ter uma produtividade tão grande e ter uma despesa médica tão grande e ter um absenteísmo tão grande, então na verdade a gente tem que começar a parar para analisar isso (...) é o estresse, o nervoso, a preocupação e eu sei de tudo isso, mas eu não posso falar isso para eles [os funcionários], eu tenho que tentar levar tranqüilidade para trabalhar a ansiedade deles. Se eu disser: "nossa é isso mesmo, com uma meta dessa ninguém consegue"... Nada disso, essas coisas a gente tem que sentir, eu internalizo isso e, muitas vezes, a gente não tem como passar. Por que tem a hora certa de passar e às vezes essa hora certa nunca chega, você vai falar uma coisa numa hora indevida e parece que você não é cúmplice de algumas idéias (...).
\end{abstract}

(Gerente 2)

Fica claro o comportamento esperado de um profissional na "ZIX": ser um "cúmplice”, transmitir propostas organizacionais como se nelas acreditasse, mesmo não concordando. Os valores da honestidade e da transparência, por exemplo, só podem ser considerados no limite em que não prejudiquem a "cumplicidade" com os interesses organizacionais. Mas ao revelar sua discordância extrapola-se a imagem do gestor como um indivíduo norteado apenas pelos interesses organizacionais, voltado ao controle de seus subordinados. Verifica-se, então, um processo no qual os agentes sociais contribuem para sua própria subjugação (Pagès et al., 1987). Lembra-se que o gestor é, também, subordinado em um outro nível.

Aparentemente há um direcionamento conjunto para os objetivos organizacionais, mas, na prática, essa ação gerencial é permeada por ambigüidades que envolvem interesses pessoais e grupais. Processo também revestido de certo dinamismo, na medida em que se mudam partes das percepções dos agentes sociais sobre o cotidiano do trabalho no qual estão inseridos. Um exemplo desse dinamismo são as mudanças de opinião do Diretor 1, após ser, por duas vezes, "carteiro por um dia”, e, pessoalmente, executar as atividades dessa categoria. A partir daí, ele chegou à conclusão de que muitas reclamações das quais discordava e ironizava eram legítimas. Após essa experiência, o diretor incentivou os gerentes a também participarem dessa "inversão da pirâmide”. Visava-se a integração organizacional, um objetivo apoiado também em diversas outras ações. 
Vários eventos foram promovidos na área de esporte, cultura e lazer, com a possibilidade de participação dos dependentes. Dentro da área social surgiram campanhas preventivas e educativas, voltadas para o cuidado com a saúde. Mas há dissenso quanto à efetividade dessas propostas. De acordo com os depoimentos analisados, por um lado, muitos gestores concordam sobre a importância dessas ações, voltadas para eventos específicos, e afirmam ser a base da integração. Por outro, vários destacam que as mesmas ações criam condições para separar a organização em grupos e colocam os próprios gestores sob dilemas e pressões adicionais, em virtude dos diferentes níveis de envolvimento e apoio nesses eventos. Isso gera conflitos entre os gestores produzindo críticas, autocríticas e discussões com argumentos como a falta de iniciativa, a carga de trabalho, a pessoalidade. Esses argumentos foram evidenciados em depoimentos sobre diversas questões, com vários gestores e em muitos níveis gerenciais. Um exemplo é o trecho do depoimento de um gestor, no qual ele faz uma autocrítica e, também, critica o responsável pela área de RH:

essas coisas para mim criam panelinhas. Existe a panelinha do futebol, a panelinha disso e daquilo. (...) Você não conseguiu unir esse empregado, incorporar ele ao todo para fazer a unidade. Um instrumento que a gente teria, mas não funciona, infelizmente, eu acho por incompetência de quem ficou a frente e tal, era a Arco [Associação Recreativa dos Correios] (...) a preocupação do gerente de RH neste período foi pessoal (...) aquela preocupação de proveito próprio, não sei se seria egoísmo, não sei o que foi (...) Mas só que eu também não estou fazendo o meu papel. (...) Eu acho que eu deixei muito a desejar nesse período com relação à política de RH. Eu tentava mais a minha política pessoal (...). Agora se eu tivesse trabalhado eu teria conseguido, se eu tivesse trabalhado mais.

(Gerente 6)

Além dessas questões, outras, mais voltadas para o processo de trabalho, também se enquadram no contexto de uma integração permeada pela diferenciação e fragmentação. Um exemplo é o processo de avaliação por meio da instrumentalização formal, a partir da implementação do gerenciamento de competência e resultados (GCR). Uma avaliação semestral, com acompanhamento durante todo o ano. Cada nível hierárquico tem metas a serem atingidas e competências a serem avaliadas, compondo parte do que é levado em conta na promoção por merecimento. Mas, novamente, surgem questionamentos sobre o fato de que as ações voltadas para a integração geram influências que podem interferir, de maneira informal, no GCR, em virtude de laços pessoais. Outra contradição está na percepção de que seria vantajoso ser um mau funcionário, pois 
às vezes, algumas pessoas são beneficiadas por aquele chefe que não quer ter trabalho com o GCR e dá a nota máxima para todo mundo (...) Às vezes tem empregado que é ruim em determinada seção e um outro que é bom na outra, aquele que é bom teve uma pontuação um pouco menor do que aquele que é $\operatorname{ruim}(\ldots)$.

(Gerente 6)

Como se não bastassem as contradições referentes a cada ação, aqui a idéia do benefício remete a um outro aspecto importante: muitas das ações e suas contradições se inter-relacionam na organização. Esse é o caso entre a avaliação e a valorização do funcionário. Quando avalio e ofereço um benefício a um funcionário em detrimento de outro, estou valorizando posições e contradições do primeiro, o que pode repercutir no segundo. Da mesma maneira as diferentes ações para valorização e suas contradições também vão se inserir nessa inter-relação. Um exemplo é a ação de valorizar o funcionário ampliando sua empregabilidade. Para alguns entrevistados qualquer um poderia estar procurando emprego no dia seguinte, até eles, o que legitimava a importância de se aperfeiçoar. Mas a segurança e a estabilidade no emprego eram valorizadas por muitos, o que mostra a ambigüidade que envolve o discurso do aperfeiçoamento contínuo, para garantir a empregabilidade em uma possível necessidade ou oportunidade de sair da empresa, convivendo com o desejo de estabilidade e segurança dentro da própria organização. Esse dilema reforça um contexto gerencial repleto de diferentes sentimentos a partir de uma mesma questão, em virtude dela envolver diversas incertezas e significados.

Entretanto, é importante destacar que, a despeito desse cenário confuso e ambíguo, os interesses organizacionais não são deixados de lado. Praticamente todos os gestores entrevistados concordam que o objetivo da organização é o lucro e que isso é algo necessário. As contradições mencionadas surgem nos caminhos para legitimar e efetivar esse objetivo, envolvendo uma diversidade de questões, tais como: a ampliação da empregabilidade do funcionário, o aumento de sua qualidade de vida e a preocupação com o seu crescimento profissional. Essas questões estão presentes de diferentes maneiras nos discursos e práticas dos gestores, muitas vezes, para justificar ações a serem tomadas e às quais tanto os funcionários, quanto, de certa maneira, eles próprios terão de se submeter.

Nesse processo, as ações dos gestores, discutidas aqui, demonstram a presença da integração, da diferenciação e da fragmentação na tentativa de disseminação de uma determinada cultura. Assim, é possível questionar os que colocam o gestor com a condição e a responsabilidade de definir uma cultura forte e homogênea para a organização. Como falar em homogeneidade, em consenso organizacional, se nem no grupo que define e direciona a gestão da organização existe tal consenso? Há necessidade 
de recontextualizar o papel dos gestores nas propostas de integração, pois esse grupo profissional, ocupante de cargos gerenciais, apresenta interesses, ambigüidades, dilemas e conflitos que o distanciam da construção de um contexto organizacional integrado, transparente e consensual.

\section{Conclusão}

As idéias nas quais se baseiam as propostas de construção de uma "cultura corporativa”, como caminho para o sucesso organizacional, são questionáveis quanto à maneira como são tratados os gestores. Colocá-los como um grupo capaz de desenvolver a integração e o consenso organizacional implica considerar seus membros como agentes que concordam, também de forma consensual e integrada, com as ações prescritas pela direção e tudo que buscam disseminar e construir. Entretanto, em virtude de ambigüidades inerentes ao contexto organizacional, parece ser mais coerente afirmar que a homogeneização da organização é, no mínimo, restrita como um todo. A integração existe, mas é parcial. Vem acompanhada da diferenciação e da fragmentação.

As subculturas e as relações de poder e interesses inseridas no cotidiano do trabalho, não são, necessariamente, falhas a serem sanadas, indicam apenas a diversidade do contexto organizacional. Algumas subculturas, oriundas ou não das ações dos gestores, podem ser favoráveis aos objetivos organizacionais, já outras podem ser desfavoráveis. No estudo de caso da "ZIX”, a própria ambigüidade associada aos gestores contribuiu para essa configuração. A origem, aparentemente, está nas pressões externas e internas à organização, em níveis organizacionais acima e abaixo do gestor, e em toda uma história de vida. $\mathrm{O}$ que remete a construções sociais que não desaparecem pelo simples desejo da direção ou do próprio gestor. Logo, o processo gerencial deste último envolve complexidades típicas de se lidar com uma diversidade de variáveis, objetivas e subjetivas, ligadas aos recursos materiais e humanos envolvidos. Um processo marcado pela mediação constante de ambigüidades provenientes dessas variáveis.

Tanto a reflexão teórica, quanto o estudo de caso apresentado reforçaram essas conclusões e embasaram a resposta à questão problematizada neste artigo: como se configura a atuação dos gestores em relação ao seu papel como componente de integração na proposta da "cultura corporativa”? Os gestores são agentes sociais, vivenciando ambigüidades inerentes aos aspectos humanos e materiais das relações organizacionais, características que permanecem mesmo quando recebem a atribuição de desenvolver atividades para a integração de todos, em torno de uma "cultura corporativa”, algo cuja inviabilidade se evidencia nos resultados de suas ações, caracterizados por uma diversidade de construções parciais. 
Essas construções parciais contêm elementos compartilhados por todos na organização e outros compartilhados por determinados grupos e/ou indivíduos de maneira mais ou menos transitória. Assim remetem, simultaneamente, para a integração, a diferenciação e a fragmentação organizacional. Portanto, dentro de uma lógica que busca a integração, a contribuição do gestor existe, mas é parcial.

Como contribuição final deste artigo, fica o alerta sobre a necessidade de se reconhecer, nos estudos sobre cultura em organizações, a parcialidade do gestor, bem como as ambigüidades que permeiam sua atuação organizacional. Talvez, só assim seja possível construir uma base de conhecimentos que permita lidar com a diversidade cultural nas organizações, envolvendo os gestores como mediadores de uma diversidade inexorável, não como construtores de uma homogeneização artificial e ilusória.

\section{Referências bibliográficas}

AKTOUF, O. O simbolismo e a cultura de empresa. In: CHANLAT, J. F. (Org.). O indivíduo nas organizações: dimensões esquecidas. São Paulo: Atlas, 1994. v. 2, p. 39-79.

ALVESSON, M. Understanding organizational culture. London: Sage, 2002.

- - SVENINGSSON, S. The good visions, bad micro-management and ugly ambiguity: contradictions of (non)leadership in a knowledge intensive organization. Organization Studies, v. 24, n. 6, p. 961-995, 2003.

; WILLMOTT, H. Making sense of management: a critical introduction. London: Sage, 1996.

BARDIN, L. Análise de conteúdo. Lisboa: Edições 70, 1977.

BERGER, P. L.; LUCKMANN, T. A construção social da realidade. 7. ed. Petrópolis: Vozes, 1985.

BOGDAN, R. C.: BIKLEN, S. K. Investigação qualitativa em educação. Porto: Porto Codex, 1994.

BOLTANSKI, L. Os executivos autodidatas. Revista de Administração de Empresas, Rio de Janeiro, v. 24, n. 1, p. 5-25, 1984.

CARRIERI, A. de P. O fim do "mundo Telemig”: a transformação das significações culturais em uma empresa de telecomunicações. 2001. 326 f. Tese (Doutorado em Administração) — Departamento de Ciências Administrativas, Universidade Federal de Minas Gerais, Belo Horizonte. 
CAVEDON, N. R. O método etnográfico em estudos sobre a cultura organizacional: implicações positivas e negativas. In: ENCONTRO NACIONAL DE PROGRAMAS DE PÓS-GRADUAÇÃO EM ADMINISTRAÇÃO, 23., 1999, Foz do Iguaçu. Anais... Foz do Iguaçu: Anpad, 1999.

; FACHIN, R. C. Homogeneidade versus heterogeneidade cultural: um estudo em universidade pública. In: ENCONTRO NACIONAL DE PROGRAMAS DE PÓS-GRADUAÇÃO EM ADMINISTRAÇÃO, 24., 2000, Florianópolis. Anais... Florianópolis: Anpad, 2000.

CHANLAT, J. F. O ser humano, um ser simbólico. In: CHANLAT, J. F. (Org.). O indivíduo nas organizações: dimensões esquecidas. São Paulo: Atlas, 1996. v. 3, p. 227-230.

DAVEL, E.; VERGARA, S. C. Gestão com pessoas e subjetividade. São Paulo: Atlas, 2001.

DEAL, T. E.; KENNEDY, A. A. Corporate cultures: the rites and rituals of corporate life. Reading, Massachusetts: Addison-Wesley, 1982.

DUPUIS, J. Antropologia, cultura e organização: proposta de um modelo construtivista. In: CHANLAT, J. F. (Org.). O indivíduo nas organizações: dimensões esquecidas. São Paulo: Atlas, 1996. v. 3, p. 231-251.

FROST, P. J. et al. (Eds.). Reframing organizational culture. Newbury Park, CA: Sage, 1991.

JAQUES, E. The changing culture of a factory. London: Tavistock, 1951.

MARTIN, J. Cultures in organizations: three perspectives. New York: Oxford University Press, 1992.

—. Organizational culture: mapping the terrain. Thousand Oaks, CA: Sage Publications, 2002.

_- FROST, P. Jogos de guerra da cultura organizacional: a luta pelo domínio intelectual. In: CALDAS, M.; FACHIN, R.; FISCHER, T. (Orgs.). Handbook de estudos organizacionais. São Paulo: Atlas, 2001. v. 2, p. 219-251.

MAYO, E. The human problems of an industrial civilization. New York: The Viking, 1960.

MELO, M. C. de O. L. Produto e produtores da cultura organizacional: algumas questões sobre o comportamento dos empregados. Revista de Administração de Empresas, São Paulo, v. 26, n. 25, p. 60-67, 1991.

Carreira gerencial: os dramas e as tramas de gerentes em organizações brasileiras. Revista Organizações \& Sociedade, Salvador, v. 17, n. 7, p. 117-128, 2000.

MEYERSON, D.; MARTIN, J. Cultural change: an integration of three different views. Journal of Management Studies, v. 24, n. 6, p. 623-647, Nov. 1987.

MINAYO, M. C. S. (Org.). Pesquisa social. 18. ed. Petrópolis: Vozes, 2001. 
MOTTA, P. R. Gestão contemporânea: a ciência e a arte de ser dirigente. 13. ed. Rio de Janeiro: Record, 2002.

OUCHI, W. Teoria z: como as empresas podem enfrentar o desafio japonês. 10. ed. São Paulo: Nobel, 1986.

PAGÈS, M. et al. O poder das organizações. São Paulo: Atlas, 1987.

PÉPIN, N. Cultura de empresa: nascimento, alcance e limites de um conceito. Mosaico: Revista de Ciências Sociais, Vitória, v. 1, n. 1, p. 267-293, 1998.

PETERS, T. J.; WATERMAN JR., R. H. Vencendo a crise. 12. ed. São Paulo: Harbra, 1986.

PFEFFER, J. Management as symbolic action: the creation and maintenance of organizational paradigms. Research in Organizational Behavior, v. 3, p. 1-52, 1981.

POIRIER, J.; CLAPIER-VALLADON, S.; RAUBAUT, P. Les récits de vie: théorie et pratique. Paris: Puf, 1983.

REED, M. The sociology of management. London: Harvester Wheatsheaf, 1989.

RODRIGUES, S. B. O chefinho, o telefone e o bode: autoritarismo e mudança cultural no setor de telecomunicações. 1991. 416 f. Tese (Professora titular) — Faculdade de Ciências Econômicas da Universidade Federal de Minas Gerais, Belo Horizonte.

SCHEIN, E. Organization cultures and leadership. San Francisco: Jossey-Bass, 1985.

SMIRCICH, L. Concepts of culture and organizational analysis. Administrative Science Quarterly, Cornell University, v. 28, n. 3, 1983.

— Science, v. 18, n. 3, p. 257-273, 1982.

TRIVIÑOS, A. N. S. Introdução à pesquisa em ciências sociais. São Paulo: Atlas, 1987.

YIN, R. K. Estudo de caso: planejamento e métodos. 2. ed. Porto Alegre: Bookman, 2001. 